\title{
Positive components of mental health provide significant protection against likelihood of falling in older women over a 13-year period
}

\author{
Richard A. Burns, ${ }^{1}$ Julie Byles, ${ }^{2}$ Paul Mitchell ${ }^{3}$ and Kaarin J. Anstey ${ }^{1}$ \\ ${ }^{1}$ Centre for Research on Ageing, Health and Wellbeing, The Australian National University, Canberra, ACT, Australia \\ ${ }^{2}$ Research Centre for Gender, Health and Ageing, University of Newcastle, Newcastle, NSW, Australia \\ ${ }^{3}$ Centre for Vision Research, Westmead Millennium Institute and Department of Ophthalmology, The University of Sydney, Sydney, NSW, Australia
}

ABSTRACT

Background: In late life, falls are associated with disability, increased health service utilization and mortality. Physical and psychological risk factors of falls include falls history, grip strength, sedative use, stroke, cognitive impairment, and mental ill-health. Less understood is the role of positive psychological well-being components. This study investigated the protective effect of vitality on the likelihood of falls in comparison to mental and physical health.

Methods: Female participants were drawn from the Dynamic Analyses to Optimise Ageing (DYNOPTA) harmonization project. Participants $(n=11,340)$ were aged $55-95$ years (Mean $=73.68$; SD $=4.31)$ at baseline and observed on up to four occasions for up to 13 years (Mean $=5.30$; SD $=2.53$ ).

Results: A series of random intercept logistic regression models consistently identified vitality's protective effects on falls as a stronger effect in the reduction of the likelihood of falls than the effect of mental health. Vitality is a significant predictor of falls likelihood even after adjusting for physical health, although the size of effect is substantially explained by its covariance with mental and physical heath.

Conclusions: Vitality has significant protective effects on the likelihood of falls. In comparison with mental health, vitality reported much stronger protective effects on the likelihood to fall in comparison with the risk associated with poor mental health in a large sample of older female adults. Both physical health and mental health account for much of the variance in vitality, but vitality still reports a protective effect on the likelihood of falls.

Key words: longitudinal studies, research design and methodology, depression

\section{Introduction}

Among adults aged 65 years and over, falls are a leading cause of unintentional injuries (Pointer et al., 2003; Scott, 2005; Stevens et al., 2008), and in those aged 75 years and over, falls are among the leading causes that contribute to the burden of disease and injury (Begg, 2007). Falls in elderly people can often result in a wide range of injuries, including soft tissue damage, head trauma, dislocations and fractures, restriction of activity, and a reduced quality of life - injuries that are exacerbated with increased age (Covinsky

Correspondence should be addressed to: Richard A. Burns, Centre for Research on Ageing, Health and Wellbeing, The Australian National University, Canberra, ACT, Australia. Phone: +61 026125 3132; Fax: +61 26125 0733. Email: Richard.Burns@anu.edu.au. Received 23 Sep 2011; revision requested 7 Jan 2012; revised version received 17 Jan 2012; accepted 17 Jan 2012. et al., 2001; Rubenstein, 2006), particularly as risk of falling increases with age and between $10 \%$ and $15 \%$ of falls are injurious (Rubenstein, 2006). Consequently, injurious falls are a leading cause of hospitalization in people aged 65 years and over, accounting for over $80 \%$ of all injury admissions to hospital (Kannus et al., 2006). Furthermore, falls account for $40 \%$ of all injuryrelated deaths (World Health Organization, Ageing and Life Course Unit, 2008), and in elderly people, the 12-month risk of mortality after hospitalization following a fall is $50 \%$ (Rubenstein, 2006). Among elderly people, head injuries specifically account for $46 \%$ of fatal falls (Stevens et al., 2006). Repeated falls and physical instability are common indicators of nursing home admissions (Rubenstein, 2006). This has important implications for health-related policy, since in Australia, for example, by 2051 
one-quarter of the Australian population will be aged 65 years and over (Australian Bureau of Statistics, 1998), a pattern that may be replicated across the globe. Rates of falling appear to vary markedly. For those adults aged over 65 years and living in the community, estimates for those who report falling once per year range from $20 \%$ to 40\% (Tinetti et al., 1988; Anstey et al., 2006; Shumway-Cook et al., 2009) in comparison with $40 \%$ to $50 \%$ of residents in aged care facilities (Kron et al., 2003). There is substantial economic burden associated with fall-related injuries. One recent international review indicated that between $0.85 \%$ and $1.5 \%$ of national healthcare expenditure in the developed world was associated with the costs of post-fall treatment (Heinrich et al., 2010).

A range of factors have been identified as risk factors for falling in older adults (Covinsky et al., 2001). These factors include physical characteristics that include having experienced a previous fall, impaired balance and gait and decreased grip strength, sedative use, and stroke (Tinetti et al., 1988; Nevitt et al., 1991; Graafmans et al., 1996; Covinsky et al., 2001). Psychological characteristics that have been identified as risk factors for falling include cognitive impairment, mental ill health, and poor self-referent attitudes relating to physical capacity (Tinetti et al., 1988; Studenski et al., 1994; Graafmans et al., 1996). Recently, the role of positive psychological constructs like morale and control has been identified as a significant predictor of falling (Anstey et al., 2008). In comparison with the effects of depression, comparative effects of control and morale were identified. While Anstey et al. (2008) analyzed the effects of positive and negative psychological functioning independently, an examination of the concurrent effects of both positive and negative psychological functioning on the risk of falling remains to be explored. There is increasing evidence for the independent effects of positive and negative psychological functioning on both mental and physical health outcomes (Ryan and Deci, 2001; Huppert and Whittington, 2003; Burns et al., 2011). While those factors that predispose individuals to increased risk of falling, such as increased age and poor physical and mental ill-health, are well demonstrated, the role of positive psychological function as a protective mechanism to reduce falling risk remains to be explored. This study assessed the combined contribution of positive and negative psychological and physical functioning toward predicting the likelihood of falls and determining whether positive or negative dimensions report comparative effects on the likelihood of falls.

\section{Methods}

\section{Participants}

Data were drawn from the Dynamic Analyses to Optimize Ageing (DYNOPTA) project (Anstey et al., 2010) that involves pooling data from nine Australian longitudinal studies of aging. The harmonization of existing studies, by pooling data or parallel analysis, is increasingly recognized as an important method that contributes to and addresses the limitations of investment in individual longitudinal studies (Noale et al., 2005). Overall, there were 50,652 respondents, aged 45-103 years, in the pooled DYNOPTA dataset at baseline, which was collected between 1990 and 2001. Of the four contributing studies to DYNOPTA that provided the necessary variables, one was the female-cohort study, the Australian Longitudinal Study of Ageing old cohorts. Consequently, a significant proportion of participants were female (93\%), so we restricted our analyses to females $(n=13,223)$ only. Also, at baseline, the reported rate of falls ranged from $14 \%$, for those aged $45-54$, to $51 \%$, for those aged 85 years and older (see Figure 1). This was consistent across the 13 years of available data. However, at subsequent observations it was clear that those who remained younger than 55 years of age over the duration of the study reported far fewer falls than those who were aged over 55 years. Subsequently, we excluded those who were younger than 55 years of age from our analyses. Therefore, our final sample size comprised women $(n=11,340)$ aged 55 years and over $($ Mean $=73.68 ; \mathrm{SD}=4.31)$ at baseline, who were observed for up to four occasions over 13 years $($ Mean $=5.30$; $S D=2.53)$.

\section{Measures}

Vitality and Mental Health

We derived variables from the Short-Form Health Survey-36 (SF-36) (Ware et al., 1998). The vitality and mental health indexes comprise the SF36 mental health component score. The vitality subscale comprises four items, including "feel full of life," "have a lot of energy," "felt worn out," and "felt tired." The mental health subscale has been validated against clinical measures of depression (Rumpf et al., 2001; Yamazaki et al., 2005) and used in epidemiological studies worldwide (Skapinakis et al., 2005; Gill et al., 2006). It comprises five items, including "been a nervous person," "felt so down in the dumps nothing could cheer you up," "felt calm and peaceful," "felt down," and "been a happy person." For both the vitality and mental health subscales, participants indicated the extent to which they experienced each statement on a 6point Likert-type scale, ranging from " 0 , none of 


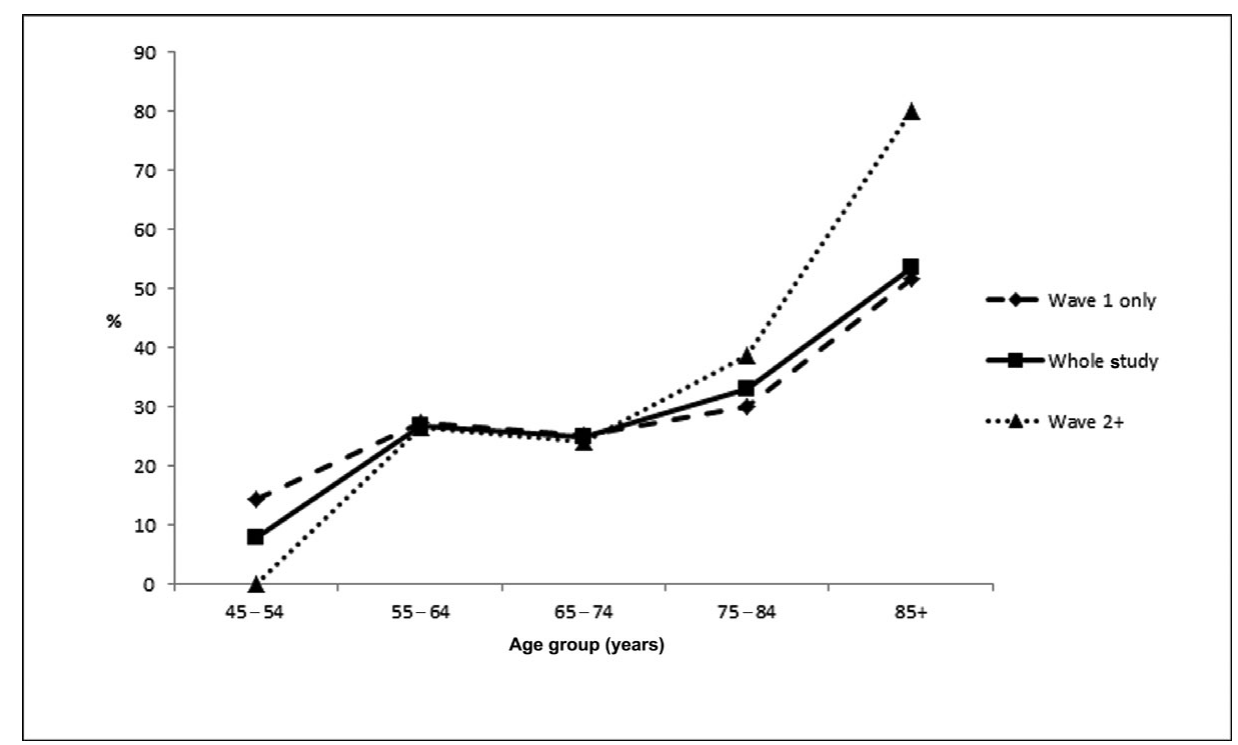

Figure 1. A comparison of the percentage of fallers by age group.

the time" to " 6 , all of the time", over the preceding four weeks.

To explore the dimensional nature of the vitality and mental health subcomponents of the SF-36 mental health scale component, we undertook a principal axis factor analysis with a Direct Oblimin rotation to determine whether the vitality and mental health items could discriminate between their parent factors. A Kaiser-MeyerOlkin's measure of sampling adequacy score of 0.879 and the Bartlett's test of sphericity $\left(\chi^{2}=\right.$ 172830.499 , df $=36, \mathrm{p}<0.001)$ revealed these items as adequate for factor analysis. Our factor analysis revealed two factors with eigenvalues $>1$, explaining $66 \%$ of the variance. A review of the loadings for each item reveals that the items loaded onto their respective parent scales at a level $\geq 0.32$, the level at which the latent factor explains $10 \%$ of an item's variance. Two exceptions were for two mental health items, "felt calm and peaceful" and "been a happy person," which reported crossloadings of 0.34 and 0.35 , respectively, on their nonparent scale. These cross-loadings were ignored since their loadings only met our inclusion criteria given the far stronger propensity of the vitality and mental health items to discriminate the two factors. We concluded that the factors were discriminate. In the DYNOPTA study, moderate cross-sectional correlations between vitality and mental health, with reported magnitudes of between $r=0.57$ and $r=0.61$, were consistently reported. Similarly, correlations between self-rated health with both vitality ( $\mathrm{r}=0.60$ to 0.62$)$ and mental health $(\mathrm{r}=$ 0.41 to 0.44 ), and correlations between physical health with both vitality $(r=0.62$ to 0.65$)$ and mental health ( $\mathrm{r}=0.23$ to 0.26$)$ were consistently reported. Despite these moderate associations, a significant amount of variance remains unexplained in either construct such as to warrant treating these variables as independent indicators of positive and negative dimensions of well-being.

FALLS

At each wave of observation, falls were ascertained from self-reports of falling to the ground in the past 12 months.

\section{COVARIATES}

Socio-demographics: We controlled for participant gender and age.

Smoking: Baseline smoking consumption was assessed in terms of never-smoker, former-smoker, or current-smoker.

Alcohol: Following the guidelines of the National Health and Medical Research Council (Australia) (NHMRC) (2001), we categorized participants' quantity and frequency of alcohol consumption to assess baseline levels of alcohol consumption as either low-risk, risky/high-risk, and abstinent.

Physical health and self-rated health: Physical Health was assessed with the SF-36 physical component score, which comprises a summation of physical function, role-physical, bodily pain, and general health (Ware et al., 1998). Self-rated health was measured using the global health item from the SF-36 which requires participants to describe their general health on a 5-point rating scale from " 1 , excellent" to " 5 , poor." Correlations between the SF-36 health variables over the four measurement occasions are reported in Table 1. Despite the reported strong correlations between some of our 
Table 1. Baseline descriptive statistics by baseline falling status

\begin{tabular}{|c|c|c|c|c|c|}
\hline & \multicolumn{2}{|c|}{$\begin{array}{l}\text { NON- } \\
\text { FALLERS }\end{array}$} & \multicolumn{2}{|c|}{ FALLERS } & \multirow{2}{*}{$\begin{array}{l}\text { COMPARISON BETWEEN } \\
\text { NON-FALLERS } \\
\text { AND FALLERS }\end{array}$} \\
\hline & $\mathrm{N} / \mathrm{M}$ & SD & $\mathrm{N} / \mathrm{M}$ & SD & \\
\hline Age (mean, SD) & 73.91 & 4.29 & 73.91 & 5.21 & $\mathrm{t}=0.6134 ; \mathrm{p}=0.483$ \\
\hline \multicolumn{6}{|l|}{ Smoking Status } \\
\hline Never-smokers & 5479 & $61 \%$ & 1368 & $57 \%$ & \multirow[t]{3}{*}{$\chi^{2}=0.4866 ; p=0.784$} \\
\hline Former smokers & 2591 & $31 \%$ & 643 & $34 \%$ & \\
\hline Current smokers & 452 & $8 \%$ & 112 & $9 \%$ & \\
\hline \multicolumn{6}{|l|}{ Alcohol consumption } \\
\hline Abstainers & 2773 & $33 \%$ & 667 & $32 \%$ & \multirow[t]{3}{*}{$\chi^{2}=0.7412 ; \mathrm{p}=0.863$} \\
\hline Low-risk drinkers & 5047 & $63 \%$ & 1179 & $64 \%$ & \\
\hline Risky drinkers & 321 & $4 \%$ & 82 & $4 \%$ & \\
\hline Self-rated health (mean, SD) & 3.06 & 0.98 & 2.88 & 0.92 & $\mathrm{t}=8.5023 ; \mathrm{p}<0.001$ \\
\hline Physical health (mean, SD) & 42.24 & 11.25 & 39.38 & 11.87 & $\mathrm{t}=10.6771 ; \mathrm{p}<0.001$ \\
\hline Vitality mean, SD & 60.33 & 20.85 & 55.31 & 22.33 & $\mathrm{t}=10.4237 ; \mathrm{p}<0.001$ \\
\hline Mental health (mean, SD) & 79.59 & 11.25 & 77.17 & 17.72 & $\mathrm{t}=6.5108 ; \mathrm{p}<0.001$ \\
\hline
\end{tabular}

variables of interest, we judged correlates not to be significantly high to reflect possible multicollinearity.

\section{Statistical analyses}

Statistical analyses were undertaken using STATA v.10. Vitality, mental, physical, and self-rated health were coded so that high scores reflected positive health status and transformed into z-scores. We implemented random intercept logistic regression to determine the effects of vitality and mental health on likelihood of falls, adjusting for sex and time as years from baseline. Further adjustments were made with the inclusion of smoking (ref: nonsmoker) and alcohol (ref: low-risk drinker) consumption, physical health, and self-rated health. We considered implementing random effects for slope of time, but when specified, very little of the variance, between $2 \%$ and $5 \%$ for our various models, was indicated at the random slope level. Most of the random variances were accounted for at the intercept.

We tested three models; all were adjusted for age and time. All models except 1a, 2a, and 3a were adjusted for smoking and alcohol consumption. Model 1a tested the effects of baseline mental health and vitality on the likelihood of reporting falls after adjustment for age and time, while model $1 \mathrm{~b}$ included an adjustment for baseline physical and self-rated health. Model 2a tested the effects of time-varying predictors on the likelihood of reporting falls, with further adjustments for baseline physical and self-rated health (model $2 \mathrm{~b}$ ) and for time-varying physical and self-rated health (model 2c). Models $3 \mathrm{a}$ to $3 \mathrm{~d}$ incorporated between- and within-person effects for mental health and vitality.
The between-person effects are constant that reflect participants' scores at baseline. To assess the withinperson change, a time-varying variable was created that reflects each individual's change from his or her baseline score. Model $3 \mathrm{~b}$ was adjusted for baseline physical and self-rated health; model 3c was adjusted for time-varying physical and self-rated health; while model $3 \mathrm{~d}$ was adjusted for betweenand within-person effects for physical and self-rated health.

\section{Results}

Descriptive statistics for the whole sample and by falling status are detailed in Table 1. Age, smoking, and alcohol were unrelated to falling status. Fallers reported poorer physical health, self-rated health, mental health, and vitality. Model 1a (Table 2) indicated low baseline vitality and mental health, which were all standardized z-scores, as associated with a $35 \%$ and $4.1 \%$ increase in odds likelihood of falling over the period of observation. Most notable is the difference in the size of effect between vitality and mental health. Similarly, in model $2 \mathrm{a}$, there was only a very small statistically significant association between time-varying mental health and likelihood of falls, but low time-varying vitality was associated with an increased likelihood of falls. A one standardized point increase in vitality was associated with a $33.9 \%$ increase in the likelihood of reporting falls. In model 3a, neither betweenperson nor within-person change in mental health was associated with the likelihood of reporting a fall. In contrast, both the between- and withinperson effects for vitality reported $41.1 \%$ and $20.8 \%$ increase in the likelihood of reporting 
Table 2. Results of random effects logistic regression analyses of the baseline, time-varying between- and within-person effects of mental health and vitality on falls

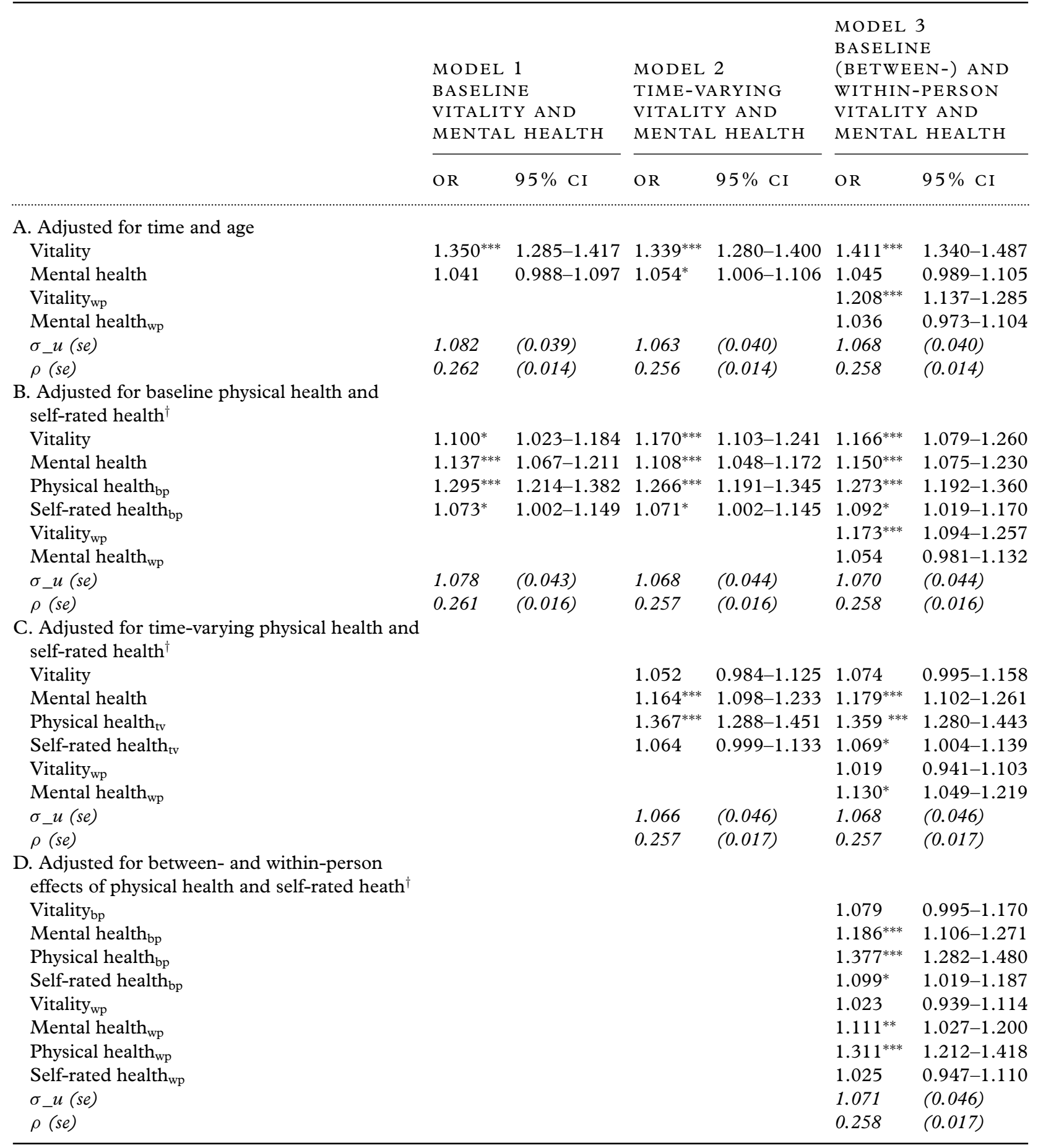

${ }^{* * *} \mathrm{p}=0.001 ; * * \mathrm{p}<0.01 * \mathrm{p}<0.05$.

${ }^{\dagger}$ Adjusted for baseline age, alcohol, and smoking.

For ease of interpretation, all predictors are reversed scored so that increased OR indicates effects for low scores on predictor variables. $\mathrm{tv}=$ time-varying variables; $\mathrm{bp}=$ between-person variables; $\mathrm{wp}=$ within-person variables; $s e=$ standard error.

falls, respectively. These results would suggest that vitality is a better predictor of the likelihood of falls than is mental health, and that increased positive psychological functioning is more protective of the likelihood of falling.
We extended our analyses to control for additional covariates, smoking and alcohol consumption, and physical and self-rated health. The reference category for smoking and alcohol were nonsmoker and low-risk drinker, respectively; 
however, in all analyses, smoking and alcohol consumption were unrelated to the likelihood of falls. In model $1 \mathrm{~b}$, results were consistent with model 1a, although the inclusion of baseline physical health appeared to explain around half of the effect in baseline vitality. When treating mental health and vitality as time-varying in model $2 b$, and controlling for baseline physical health and self-rated health, vitality again reported a strong effect on the falls likelihood with low vitality associated with $17 \%$ increase in the likelihood of reporting falls. In comparison, poor mental health was associated with a $10.8 \%$ increase in the likelihood of reporting falls. The influence of physical health appears to be the strongest in crosssectional analyses. For example, results in model $2 c$, which included time-varying physical and selfrated health, reflected results for model $1 b$, which indicated that around half of the effect for vitality is accounted for by physical health. Consistently, either very small or nonsignificant effects for selfrated health were reported between models.

Further investigation of the between- and withinperson change in vitality and mental health (model 3b) indicated that controlling for baseline physical and self-rated health, and after adjustment for smoking and alcohol, did little to change the effects for between- and within-person vitality and mental health on the likelihood of reporting falls. However, the inclusion of time-varying (model $3 \mathrm{c}$ ) and withinperson change (model $3 \mathrm{~d}$ ) in physical and selfrated health did impact on the reported effects of vitality and mental health. In most instances, half of the between- and within-person vitality effects were accounted for by the inclusion of the physical and self-reported health variables, while the mental health effects were mostly consistent across all models. For instance, by comparing model $3 \mathrm{a}$ and model $3 \mathrm{~d}$, which included the betweenand within-person physical and self-rated health variables, the increased likelihood of reporting falls for between-person vitality dropped from $41.1 \%$ to $7.9 \%$, while the within-person vitality effect dropped from $20.8 \%$ to $2.3 \%$. In contrast, the between- and within-person mental health effect increased from $4.5 \%$ to $18.6 \%$ and $3.6 \%$ to $11.1 \%$ respectively.

\section{Post-Hoc AnALysis}

Since our earlier analyses compared the effect of vitality and mental health, a post-hoc analysis comparing the effect of vitality and physical health, excluding the mental health variable, allowed us to determine the degree to which the vitality effect is explained by physical health. A comparison of between- and within-person vitality and physical
Table 3. Comparison of the effects of vitality and physical health on the likelihood of falling*

\begin{tabular}{|c|c|c|}
\hline & OR & $95 \% \mathrm{CI}$ \\
\hline Physical health $_{\mathrm{bp}}$ & $1.305^{* *}$ & $1.219-1.398$ \\
\hline Physical health $_{\mathrm{wp}}$ & $1.271^{* *}$ & $1.178-1.372$ \\
\hline Self-rated health & 1.053 & $0.977-1.132$ \\
\hline Self-rated health & 1.001 & $0.926-1.083$ \\
\hline Vitality $_{b p}$ & $1.200^{* *}$ & $1.120-1.285$ \\
\hline Vitality $_{\mathrm{wp}}$ & $1.081^{* *}$ & $1.002-1.167$ \\
\hline$\sigma_{-} \mathrm{u}(\mathrm{se})$ & 1.080 & $(0.039)$ \\
\hline$\rho(\mathrm{se})$ & 0.262 & $(0.014)$ \\
\hline
\end{tabular}

** $\mathrm{p}<0.001$.

*Adjusted for baseline age, alcohol, and smoking.

For ease of interpretation, all predictors are reversed scored so that increased OR indicates effects for low scores on predictor variables. bp: between-person variables; wp: within-person variables; se: standard error.

health effects, excluding mental health (Table 3), indicated an effect for vitality that was comparable with effects in models $1 \mathrm{a}, 2 \mathrm{a}$, and $3 \mathrm{a}$, and supports its utility as a mechanism for falls risk reduction.

We plotted the effect of varying baseline and time-varying vitality and mental health on rates of falling in four separate scenarios (Figures 2ad), to visually demonstrate the effect of different levels of vitality and mental health on rates of falling, over time. These plots reflect individuals who at baseline were aged 73 years of age (mean age in this sample), never smokers and low-risk drinkers, unadjusted for physical health due to the confounding effects reported in this study. In all scenarios, the proportion of fallers increases over time (increasing age). Specifically, in scenario 1 , the proportion of fallers is moderated by the level (average, low, and high) of vitality at baseline (Figure 2a). In contrast, in scenario 2 (Figure $2 b$ ), moderating the level of mental health at baseline appears to have little impact on the proportion of fallers over time. Similar to scenario 1 , scenario 3 (Figure 2c) again indicates the effect of different levels of vitality on proportion of fallers over time. In this case, increasing vitality was associated with lower proportions of fallers over time, while a decline in vitality was associated with higher rates of fallers. Finally, in scenario 4 (Figure 2d), change in levels of mental health was unrelated to changes in the proportion of fallers. Consequently, we would emphasize the benefit in targeting positive psychological functioning.

\section{Discussion}

Our primary aim was to compare the role of positive psychological vitality with indices of mental and physical health in predicting the likelihood of falling in the DYNOPTA sample over time. In 


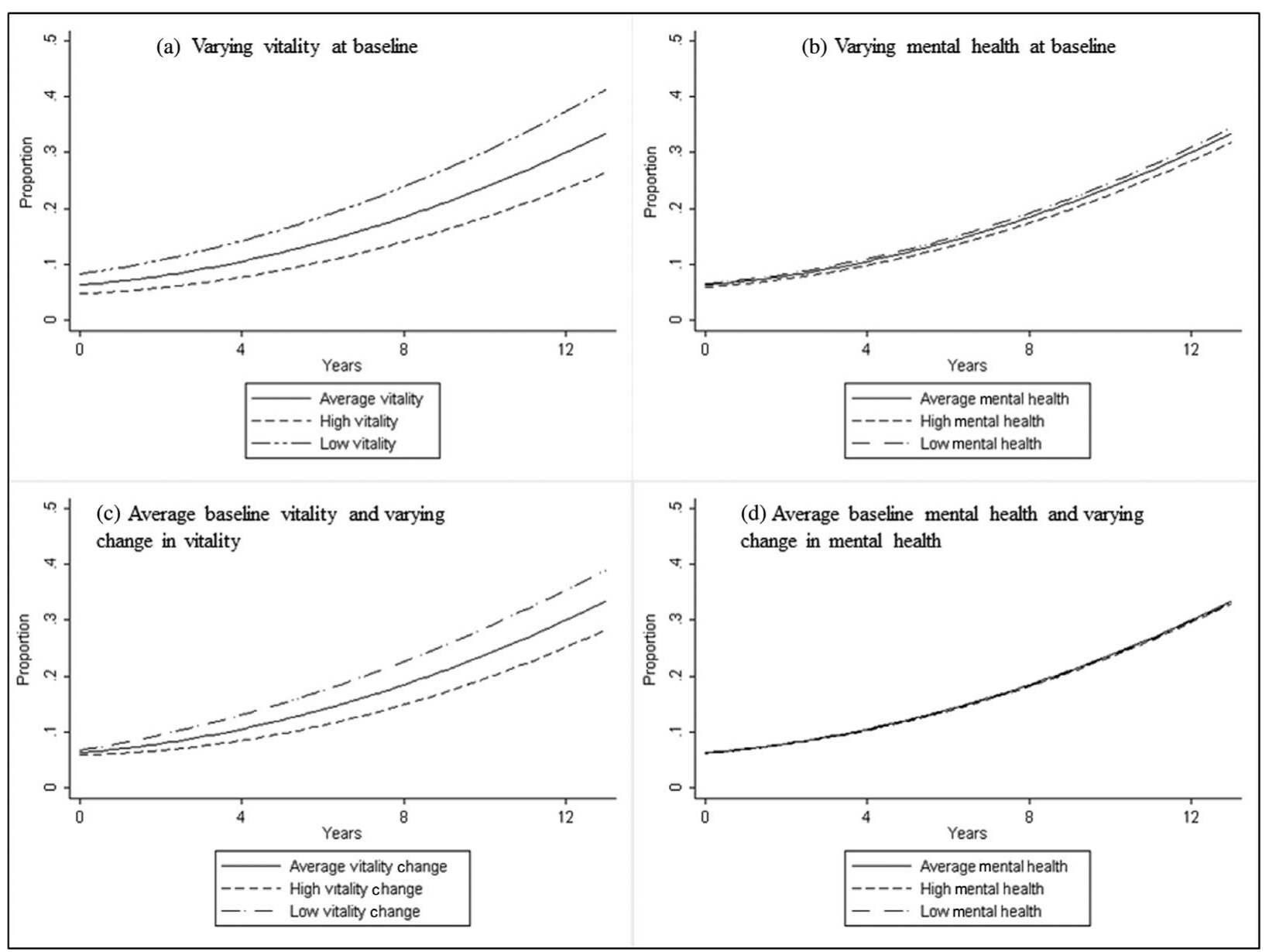

Figure 2. Plots to compare the effects of (a), varying baseline vitality (b), varying baseline mental health (c), time-varying baseline vitality, and (d) time-varying baseline mental health on the proportion who report falls over a 13-year period.

all unadjusted analyses, vitality reported a much stronger protective effect on the likelihood of having a fall in comparison with the risk associated with poor mental health. In contrast, the inclusion of within-person change in physical health accounted for a large portion of the vitality effects, but we argue that this does not negate the importance of vitality. Indeed, the reduction in vitality effect can be explained by the strong inter-correlations between positive and negative mental health components and physical health. The correlations reported here (see Table 1) between the SF-36 health variables indicate strong relationships between vitality, physical, and mental health. Whilst vitality was more strongly related to mental health than to the physical health variables, vitality was more strongly related to the physical health variables than was the mental health variable. Consequently, the inclusion of both physical health and mental health variables accounted for much of the variance in vitality. That vitality should continue to report some effect after adjusting for all these covariates still needs to be highlighted.
A post-hoc analysis compared the effect of vitality and physical health, excluding the mental health variable, in order for us to determine the degree to which vitality effect is explained by physical health. Effects for vitality were comparable whether adjusting for physical or mental health only and support its utility as a mechanism for falls risk reduction. That the effect for vitality is so strongly influenced by within-person change in physical health indicates that there is a strong association between physical health and vitality that needs to be further explored. Three distinct hypotheses need to be tested: (1) Does vitality predict change in physical health? (2) Conversely, does physical health predict change in vitality? or (3) Is there a common cause that determines change in physical health and vitality concurrently?

Prior discussion on the factorial structure of the SF-36 (Ware et al., 1998; Windsor et al., 2006) has indicated that the mental health and vitality scales load onto separate factors from the physical health variables and warrant distinguishing between physical and psychological health as related but 
independent factors. Analysis of the DYNOPTA sample supports the discrimination of physical and mental health components from their a priori structure (Bartsch et al., 2011). Furthermore, the current authors have undertaken factorial analysis of the SF-36 vitality, mental health, and physical function items within the DYNOPTA (not reported here) and indicated that the vitality and mental health items are more related to each other, supporting the notion that the mental component is distinct from the physical health component. In a yet-to-be-published study, the authors have found that the vitality and mental health items reflect distinct lower order factors of a higher level mental component as hypothesized in the $\mathrm{SF}-36$ measurement. Consequently, while there is a degree of inter-factor correlation, there is still enough distinction to warrant conclusions over the independent effects of positive and negative dimensions of psychological function (vitality and mental health) and physical health.

\section{Limitations}

While we believe that a large sample size, followed for up to four observations over a 13-year period, provides a level of robustness to our findings, a number of limitations to the study design need to be highlighted. First, due to the inclusion of two female-cohort studies, males contributed less than $10 \%$ of the sample for whom available vitality, mental, health and falls data were available. Consequently, our analyses pertain to females only. Further investigation should utilize data from male participants in the DYNOPTA study, as their sample size $(n=876)$ would suggest that an independent investigation of the role of positive psychological functioning on the likelihood to fall in males would still be informative. Other limitations include the reliance on self-report assessments for our variables of interest, particularly the lack of a clinical psychiatric mental health assessments, objective physical health assessments, and selfreported falls. However, the SF-36 has been validated against benchmarks of physical and mental health (Ware and Gandek, 1998; Rumpf et al., 2001; Skapinakis et al., 2005). Also, one meta-analysis reported high specificity (91\% to $95 \%$ ) and acceptable sensitivity ( $80 \%$ to $89 \%$ ) with self-reporting methods of recording falls in comparison with the prospective calendar method, the gold standard method for reporting falls (Ganz et al., 2005).

\section{Conclusions}

In conclusion, vitality reports stronger effects on likelihood of falling than mental health and is comparable with the effects of physical health. However, when adjusting for vitality, mental, and physical health simultaneously, much of the variance in vitality is accounted for by its strong cross-sectional associations with mental and physical health. Despite this, even when controlling for mental and physical health, between- and within-person effects for vitality are still reported and strongly indicate its utility in predicting the likelihood of falls in a sample of elderly women. We conclude that vitality and related positive psychological constructs provide individuals with a degree of protection from the likelihood of falling. Subsequent research should determine the dynamic reciprocal nature of the relationships between positive and negative psychological and physical health constructs, which are so strongly related with important health outcomes like falling.

\section{Conflict of interest}

None.

\section{Description of authors' roles}

All authors have read and approved the final version of this paper. Specifically, RAB formulated the research question, determined the analytical methods and undertook the statistical analysis, and led the writing of the paper. JB supervised the data collection, contributed to the analytical method and analyses, and contributed to the writing of the paper. PM supervised the data collection and contributed to the writing of the paper. KJA supervised the data collection, contributed to the analytical method and analyses, and contributed to the writing of the paper.

\section{Acknowledgments}

This work was supported by a National Health and Mental Medical Research Council grant (\# 410215). The data on which this research is based were drawn from several Australian longitudinal studies, including the Australian Longitudinal Study of Ageing (ALSA), the Australian Longitudinal Study of Women's Health (ALSWH), the Australian Diabetes, Obesity and Lifestyle Study (AusDiab), the Blue Mountain Eye Study (BMES), the Canberra Longitudinal Study of Ageing (CLS), the Household, Income and Labour Dynamics in Australia study (HILDA), the Melbourne Longitudinal Studies on Healthy Ageing (MELSHA), the Personality and Total Health Through Life Study (PATH), and the Sydney Older Persons Study (SOPS). These 
studies were pooled and harmonized for the Dynamic Analyses to Optimize Ageing (DYNOPTA) project. All studies would like to thank the participants for volunteering their time to be involved in the respective studies. Details of all studies contributing data to DYNOPTA, including individual study leaders and funding sources, are available on the DYNOPTA website (http://DYNOPTA.anu.edu.au). The findings and views reported in this paper are those of the authors and not those of the original studies or their respective funding agencies. Anstey is funded by an NHMRC Fellowship \#1002560.

\section{References}

Anstey, K. J., Sanden, C. V. and Luszcz, M. A. (2006). An 8 -year prospective study of the relationship between cognitive performance and falling in very old adults. Fournal of the American Geriatrics Society, 54, 1169-1176.

Anstey, K. et al. (2008). Psychological well-being is an independent predictor of falling in an 8-year follow-up of older adults. Fournals of Gerontology Series B: Psychological Sciences and Social Sciences, 63, 249-257.

Anstey, K. J. et al. (2010). Cohort profile: the Dynamic Analyses to Optimize Ageing (DYNOPTA) project. International Fournal of Epidemiology, 39, 44-51.

Australian Bureau of Statistics (1998). Population Projections 1997 to 2051. Cat. No. 3222.0. Canberra, Australia: ABS, Australian Government Publication Services.

Bartsch, L. J., Butterworth, P., Byles, J. E., Mitchell, P., Shaw, J., and Anstey, K. J. (2011). Examining the SF-36 in an older population: analysis of data and presentation of Australian adult reference scores from the Dynamic Analyses to Optimise Ageing (DYNOPTA) project. Quality of Life Research. 20, 1227-1236.

Begg, S. (2007). The Burden of Disease and Injury in Australia 2003. Canberra, Australia: Australian Institute of Health and Welfare.

Burns, R. A., Anstey, K. J. and Windsor, T. D. (2011). Subjective well-being mediates the effects of resilience and mastery on depression and anxiety in a large community sample of young and middle-aged adults. Australian and New Zealand Fournal of Psychiatry, 45, 240-248.

Covinsky, K. E. et al. (2001). History and mobility exam index to identify community-dwelling elderly persons at risk of falling. Fournals of Gerontology Series B: Psychological Sciences and Social Sciences, 56, 253-259.

Ganz, D. A. et al. (2005). Monitoring falls in cohort studies of community-dwelling older people: effect of the recall interval. Fournal of the American Geriatrics Society, 53, 2190-2194.

Gill, S. C. et al. (2006). Mental health and the timing of men's retirement. Social Psychiatry and Psychiatric Epidemiology, 41, 515-522.

Graafmans, W. C. et al. (1996). Falls in the elderly: a prospective study of risk factors and risk profiles. American fournal of Epidemiology, 143, 1129-1136.
Heinrich, S. et al. (2010). Cost of falls in old age: a systematic review. Osteoporosis International, 21, 891-902.

Huppert, F. A. and Whittington, J. E. (2003). Evidence for the independence of positive and negative well-being: implications for quality of life assessment. British fournal of Health Psychology, 8, 107-122.

Kannus, P. et al. (2006). Preventing falls among elderly people in the hospital environment. Medical fournal of Australia, 184, 372-373.

Kron, M. et al. (2003). Risk indicators for falls in institutionalized frail elderly. American fournal of Epidemiology, 158, 645-653.

National Health and Medical Research Council (Australia) (2001). Australian Alcohol Guidelines: Health Risks and Benefits. Canberra, Australia: National Health and Medical Research Council.

Nevitt, M. C. et al. (1991). Risk factors for injurious falls: a prospective study. Fournal of Gerontology, 46, M164-M170.

Noale, M. et al. (2005). Predictors of mortality: an international comparison of socio-demographic and health characteristics from six longitudinal studies on aging: the CLESA project. . Experimental Gerontology, 40, 89-99.

Pointer, S., Harrison, J. and Bradley, C. (2003). National Injury Prevention Plan Priorities for 2004 and Beyond: Discussion Paper. Canberra, Australia: Australian Institute of Health and Welfare.

Rubenstein, L. Z. (2006). Falls in older people: epidemiology, risk factors and strategies for prevention. Age and Ageing, 35 (Suppl. 2), ii37-ii41.

Rumpf, H. J. et al. (2001). Screening for mental health: validity of the MHI-5 using DSM-IV Axis I psychiatric disorders as gold standard. Psychiatry Research, 105, 243-253.

Ryan, R. M. and Deci, E. L. (2001). On happiness and human potentials: a review of research on hedonic and eudaimonic well-being. Annual Review of Psychology, 52, 141-166.

Scott, H. (2005). Research shows how we can prevent falls in old age. British fournal of Nursing, 14, 245.

Shumway-Cook, A. et al. (2009). Falls in the medicare population: incidence, associated factors, and impact on health care. Physical Therapy, 89, 324-332.

Skapinakis, P. et al. (2005). Mental health inequalities in Wales, UK: multi-level investigation of the effect of area deprivation. British fournal of Psychiatry, 186, 417422.

Stevens, J. A. et al. (2006). The costs of fatal and non-fatal falls among older adults. Injury Prevention, 12, 290-295.

Stevens, J. A. et al. (2008). Self-reported falls and fall-related injuries among persons aged $\geq 65$ years-United States, 2006. Fournal of Safety Research, 39, 345-349.

Studenski, S. et al. (1994). Predicting falls: the role of mobility and nonphysical factors. Fournal of the American Geriatrics Society, 42, 297-302.

Tinetti, M. E. et al. (1988). Risk factors for falls among elderly persons living in the community. Nerw England fournal of Medicine, 319, 1701-1707.

Ware, J. E., Jr. and Gandek, B. (1998). Overview of the SF-36 Health Survey and the International Quality of Life Assessment (IQOLA) Project. Fournal of Clinical Epidemiology, 51, 903-912. 
Ware, J. E., Jr. et al. (1998). The factor structure of the SF-36 Health Survey in 10 countries: results from the IQOLA project. International Quality of Life Assessment. Fournal of Clinical Epidemiology, 51, 1159-1165.

Windsor, T. D. et al. (2006). Measuring physical and mental health using the SF-12: implications for community surveys of mental health. Australian and New Zealand fournal of Psychiatry, 40, 797-803.
World Health Organization, Ageing and Life Course Unit (2008). WHO Global Report on Falls Prevention in Older Age. \#9789241563536. Geneva: World Health Organization. Yamazaki, S., Shunchi, F. and Green, J. (2005).

Usefulness of five-item and three-item mental health inventories to screen for depressive symptoms in the general population of Japan. Health and Quality of Life Outcomes, 3, 48. 